\title{
Folletería mexicana del siglo XIX
}

\section{José Maria Muriá}

Al caer el emperador Agustín I, de golpe y porrazo se abrió ante la ciudadanía la posibilidad de leer, decir e, incluso, escribir lo que a cada quien mejor pareciese. Era una experiencia totalmente nueva que no dejó de preocupar y hasta de horrorizar a los espíritus más conservadores.

La verdad es que la ciudadania estaba tan poco dispuesta al ejercicio de una libre imprenta que no faltaron algunos desvarios. Sin embargo, la libertad de imprenta de aquellos tiempos produjo una proliferación y un desarrollo de las artes gráficas que, andando el tiempo, tal y como ha mostrado Miguel Mathes, derivaría en manifestaciones tipográficas de primerísima calidad.

Pero antes de llegar a la era de las grandes y bellísimas ediciones cuando el siglo XIX empezaba a declinar, hubo una época comprendida entre los años de 1823 y 1860 que muy bien podria denominarse edad de la folleteria.

Ante la carencia de opciones periodísticas como las que surgirían después, todo aquél que deseara decir algo y podía costearlo, mandaba imprimir un folleto al taller de su preferencia, resultando de ahí publicaciones de la más variada índole que, por.su llaneza, agresividad e, incluso, sentido del humor, mucho contrastan con la austeridad casi monotemática de los textos impresos durante la época colonial. La enorme colección de Misceláneas de la Biblioteca Pública del Estado de Jalisco constituye una excelente muestra de este tipo de literatura, pues ahi se reunieron todos aquellos folletos que, por una suerte o por otra, acabaron en el enorme repositorio.

Hereje la tapatia porque no fia, El compadre de la tapatia, Pronta y oportuna respuesta al papel titulado Hereje la tapatía porque no fía, Retobos de la tapatia a su inoportuno respöndón, Otra zurra a la tapatia por retobada y por impia, ${ }^{2}$ son sólo una muestra de cómo en 1824 se sustentaba una polémica sobre un tema que un lustro antes hubiera llevado a varios a prisión: el de la libertad de cultos, por cierto uno de los temas más socorridos en esta folletería.

Otro tema es el de la comunicación del obispo con su grey y, por supuesto, sermones y más sermones. Otro, el de las proclamas politicas $y$, naturalmente, no falta el de la contienda politica: en favor o en contra del federalismo, de la libertad de imprenta, del centralismo, de Iturbide y de Santa Anna, o cualquiera que fuere

1 Miguel, Mathes, La litografia en México (Ms).

2 Cfr. Miscelánea, núm. 16, Biblioteca Pública del Estado de Jalisco.

" Asi lo mostró Alma Dorantes en su libro La intolerancia religiosa en Jalisco. México. INAH. 1976, (col. Cuadernos de los Centros Regionales, núm. 29). 
el gobernante en turno.

Finalmente llegamos a los discursos. No contentos con haber congratulado al auditorio, con frecuencia, los que hicieron uso de la palabra en ocasiones solemnes no quisieron dejar que los conceptos derramados entre la ciudadanía presente se disolvieran en el viento y su huella desapareciera; de tal modo, una vez comprobada ante el público la calidad del texto, acababa éste pasando por la imprenta -a costa siempre del autor-para ser distribuido entre parientes, amigos y enemigos...

Muchos hay de estos cívicos discursos en las Miscelaneas de la Biblioteca Pública de Jalisco, en el Fondo José María Lafragua de la Biblioteca Nacional de México y en la Biblioteca Sutro de San Francisco, California. Es evidente que también los hay en otras partes, pero es probable que sea en estos tres acervos donde se encuentren con mayor abundancia.

Los motivos de estos textos son también diversos. tanto como lo eran las fiestas cívicas, mismas que, al parecer, es hábito del ser humano que se conmemoren siempre y en todas partes con sonoros discursos. Los hay sobre batallas, ganadas con valor o perdidas con gran dignidad; sobre próceres, en el día de su nacimiento o de su muerte: en favor de tal o cual causa y, como es natural, abundan aquéllos que fueron proferidos con motivo del día de la patria, por encargo de las autoridades competentes.

Solamente que en este sentido, los mexicanos de la época de la folleteria -del segundo cuarto del siglo XIX - vivieron confundidos entre la celebración del 16 de septiembre -cuando Hidalgo y Costilla inició una fallida revuelta popular en 1810- o del 27 de septiembre -cuando Iturbide entró a la ciudad de México en son de triunfo de una revuelta por demás elitista.

En consecuencia, durante muchos años fueron celebradas ambas fechas, haciéndose mayor hincapié en una o la otra si el gobierno en turno era liberal-federalista o centralista-conservador.

Finalmente, acabó sobreponiéndose la celebración del día 16. A fines del siglo XIX, el día 27 de septiembre pasaba ya prácticamente como un dia cualquiera. ¿Seria por la preferencia que el longevo gobierno de Don Porfírio Díaz Mori tuvo por el sentido revolucionario de Hidalgo y Morelos o porque el dictador había nacido el día de San Porfirio, esto es, el día 15 de septiembre?

Lo que sí sabemos con certeza es que a esta coincidente circunstancia se debe el hecho de que el llamado "Grito", que rememora anualmente el llamado de Miguel Hidalgo a tomar las armas, aún hoy se sigue dando a las once de la noche del dia 15, de acuerdo con los tiempos en que el Palacio Nacional y el Palacio de Gobierno de cada entidad federativa eran escenarios de elegantes saraos que reunian a "las mejores familias" de la localidad para celebrar el presidencial cumpleaños, mientras en la correspondiente plaza el pueblo se agolpaba en una verbena popular, comía los llamados antojitos, gozaba de los fuegos de artificio y bebia a más no poder.

Pero nada de esto les tocó a los mexicanos en la era de la folletería. Para ellos el 16 de septiembre era una austera fiesta, como cualquier otra, en la que un orador principal ocupaba la tribuna y Ianzaba un mensaje alusivo a la gesta de los insurgentes y de la independencia, pero siempre imbricado con la circunstancia del 
momento. Esto es muy importante y, en última instancia, es lo que da mayor relevancia al estudio de esta literatura.

No es tanto lo que pueda decir o aportar para el conocimiento y comprensión de lo ocurrido a partir de 1810, máxime que en este sentido la información de los oradores era generalmente pobre, su perspectiva muy limitada y mínima su posibilidad de reflexión. No podia ser de otra manera porque la tribuna, aunque a veces hubiera sido ocupada por personajes destacados en ese momento o poco después, casi todos fueron individuos trascendentes por su personalidad politica y por su capacidad de historiar.

De los que hablaron oficialmente un 16 de septiembre en la capital del país durante la época de la folleteria, por ejemplo, sólo Mariano Otero, Epifacio Jesús de los Ríos y José Ma. Iglesias hicieron en algún momento algunas incursiones historiográficas.

Sin embargo, la fama de ellos se debe a otros quehaceres, político en el primero y último casos y literario en el segundo.

$\mathrm{Si}$ hemos de aceptar que la objetividad absoluta es imposible entre los historiadores, puesto que aun el más cuidadoso, frio e imparcial de ellos deja traslucir en su trabajo elementos de su propia época y personalidad, con mayor razón la circunstancia propia del autor debe hacerse presente en las palabras de quien no tiene ni la razón ni la intención de que ello no suceda. Más aún: la mayoría de estos oradores, jurisconsultos, militares y algún literato, todos ellos eminentemente políticos, usaron de forma consciente el tema de la independencia como un marco de referencia o un punto de partida para aludir a cuestiones que les eran contemporáneas.

En consecuencia, puede afirmarse, reiterando, que el conjunto de estos discursos, si bien son de escaso valor para el estudio del tema aparente o del motivo que los ocupa, son, en cambio, de una importancia extraordinaria para el estudio de la época en que fueron hechos o para penetrar en el conocimiento del momento en que cada uno fue pronunciado.

Ya es significativo, de primera intención, el personaje elegido por el gobierno para subir al podio e incluso el hecho de que exista o no la publicación del caso.

Con excepciones, casi todos los oradores habian ocupado, ocupaban o habrian de ocupar cargos muy importantes en la administración pública mexicana: diez de ellos - de veintitrés localizadoscontarian con el cargo de ministro en su curriculum vitae y con el de Presidente de la República: Manuel Gómez Pedraza ya lo había sido cuando subió al estrado en 1842 , en tanto que José Ma. Iglesias, quien habló en 1848, habría de serlo casi treinta años después, en 1876, aunque en circunstancias por demás confusas y especiales.

Sin embargo, hubo otros oradores de menor significación cuya huella se ha borrado prácticamente: de seis no se ha sabido nada. Lo curioso es que tres se suceden en la primera época centralista, a partir de 1833 , lo cual indica que este régimen no dió tanta importancia como otros al día 16 de septiembre.

En cambio, a partir de 1842 , se siente que las cartas son mejores: el expresidente Gómez Pedraza, Mariano Otero -la figura del momento- y un prócer viviente como Andrés Quintana Roo. Se trata de una época federal. 
Asimismo, tal como se apuntó, la temática corre paralela con las circunstancias. En 1822, un señor que firma A. A. recalca que Hidalgo nunca habló de independencia sino de amor a Fernando VII, mientras que Francisco de Azcárate, en 1826, rememora la época en que fue encarcelado junto con los demás miembros del ayuntamiento de México en 1808.

A José Manuel de Herrera, exministro de Relaciones Exteriores, en 1829 le preocupaba la posible reconquista por parte de España y se inspiraba en la historia reciente para exhortar a mantener la independencia.

En cambio, en 1830 , ya entregada por los españoles la plaza de San Juan de Ulúa, Manuel Sánchez de Tagle exhortó, optimista, a cumplir las leyes y a gozar de la libertad, la propiedad y la seguridad individual, mientras que, en 1831, Francisco Molina del Campo se preocupó por la presencia de aventureros en las costas, y José Dominguez, José Ma. Castañeda y José Ma. Aguilar llamaron a la concordia interior en una época de constantes enfrentamientos civiles.

Renació el optimismo con Manuel de Barrera, Ignacio Sierra y Juan de Dios Cañedo -1837, 1838 y 1839-, uno exhortando a la educación, el otro a acatar las leyes, y el tercero a cobrar ánimo para salir de la postración, en tanto que José Ma. Tornel, en 1840, proclamó: "Aliento mexicano: aún es tiempo de reparar lo perdido y de alzar un templo a la celestial concordia" y, en 1842, Gómez Pedraza habló de las grandes posibilidades del país y lo promisorio del futuro si se hacían las cosas bien.

Mariano Otero también fue optimista. De hecho, en mayor o menor medida, todos lo fueron, pero el ilustre tapatio por primera vez en tal tribuna, llamó en 1843 a sostener la República Democrática que se acababa de conseguir en tanto que, un año después, el presbítero diputado Joaquín Ladrón de Guevara prefirió insistir en la unión. Quintana Roo, en cambio, a pesar de ser un hombre tan polémico, con la perspectiva de su edad prèfirió en 1845 la reflexión de lo que para él era ya autobiografía.

Dos ausencias significativas en 1846 y 1847: no hubo ceremonia a causa de la guerra con Estados Unidos y, como es de suponerse, en 1848, José Ma. Iglesias, analizó la derrota y señaló las causas.

A un general pesimismo deben haberse enfrentado Francisco Modesto de Olaguíbel en 1849, y José Ma. Castillo en 1850 , pues se dedicaron a insistir en que la independencia habia sido benéfica para los mexicanos y las luchas de los próceres de 1810 no habían sido estériles. Epifacio de los Ríos, en 1851, censuró las guerras civiles y, ante el negro panorama no atinó más que a exclamar ¡Quiera el cielo poner remedio a los males que le afligen!

Volvió a exhortar a la unión Cástulo Barreda en 1857, y renació el optimismo en 1857 , pero José Ma. Revilla y Pedreguera apuntó a los posibles conflictos internacionales y llamó al respaldo al nuevo gobierno. Pidió insistentemente la unión en vísperas de la mayor guerra civil.

¿Qué diría Pascual Almazan al subir a la tribuna en 1859 , cuando la mayor lucha fraticida del siglo XIX estaba en su apogeo?

Este ha sido un breve, brevísimo, señalamiento de las inagotables posibilidades cognoscitivas que ofrece este material legado por los mexicanos del siglo XIX, aunque, curiosamente, después de 
la guerra civil $1857-1860$ y de hacer frente con éxito a la intervención extranjera de 1862 a 1867 , la tónica cambió por completo. Además de grandes y bellas ediciones e innumerables libros, las prensas mexicanas empezaron a publicar periódicos y el folleto quedó en el pasado.

\section{Bibliografía}

A. A. Elogios del Serenisimo Señor Don Miguel de Hidalgo y Costilla, y motivos porque este invicto Gefe dió la voz de Independencia en América. México, Imprenta de D. J. M. Benavente y socios, 1822.

Juan Francisco de Azcárate, Elogio patriótico que pronunció el ciudadano... el dia diez y seis de setiembre del año de mil ochocientos veinte y seis, en la plaza mayor de México..., México, Imprenta del Aguila, 1826.

José Manuel de Herrera, Oración patriótica que en la plazuela principal de la alameda de México pronunció... el 16 de setiembre de 1829 aniversario del grito de Dolores, México, Imprenta del Aguila, 1829.

Francisco Manuel Sánchez de Tagle, Arenga civica que en 16 de setiembre de 1830, aniversario del glorioso grito de Dolores pronunció en memoria de él, en la plaza mayor de México, el C. ..., elegido al efecto por la junta patriótica, México, Imprenta del Aguila, 1830.

Francisco Molinos del Campo, Discurso pronunciado el 16 de setiembre de 1831, aniversario del glorioso pronunciamiento de Dolores, por el C...., en la capital de los Estados-Unidos Mexicanos, México, Imprenta del Aguila, 1831.

José Domínguez Manso, Discurso que el C. ..., Ministro de la Suprema Corte de Justicia, pronunció en la Aula General de la Nacional y Pontificia Universidad de la Ciudad de México, en 16 de setiembre de 1832, en celebridad del aniversario del glorioso grito de Dolores, México, Imprenta del Aguila, 1832.

José María Castaneta y Escalada, Oración civica que pronunció en la alameda de la Ciudad Federal el ciudadano ... A 16 de setiembre de 1834, México, Imprenta de Galván, 1834.

José Marîa Águilar de Bustamante, Discurso pronunciado en la plazuela principal de la alameda de la capital de la República Mexicana por el ciudadano .... el 16 de setiembre de 1836, aniversario del justo grito de Dolores, apellidando Independencia Nacional, México, Ignacio Cumplido, 1837.

Manuel de la Barrera y Troncoso, Discurso pronunciado por el ciudadano licenciado .... el dia 16 de setiembre de 1837, México, Ignacio Cumplido, s. f.

Ygnacio Sierra y Rosso, Discurso pronunciado en México el 16 de setiembre de 1838 por el ciudadano .... contador de la Dirección General de Rentas, teniente coronel, fiscal general de artilleria e ingenieros, individuo del ilustre Colegio de Abogados y de otras varias academias y corporaciones cientificas, México, Imprenta del Iris, 1838.

Juan de Dios Cañedo, Discurso que pronució el Escmo. Señor D. ... en el solemne aniversario del glorioso grito de Dolores, la mañana del 16 de setiembre de 1839, México, Ignacio Cumplido, 1839.

José María Tornel y Mendivil, Discurso que pronunció el Escmo. Señor General D. ..., individuo del Supremo poder conservador en la alameda de la ciudad de México, en el día del solemne añiversario de la Independencia, México, Ignacio Cumplido, 1840. 
'Manuel Gómez Pedraza, Oración encomiástica que el ciudadano ... dijo el dia 16 de setiembre de 1842, aniversario de la gloriosa proclamación de la Independencia el año de 1810. México, Imprenta de Vicente Garcia Torres, 1842.

Mariano Otero, Oración cívica que el ciudadano Lic. ... pronunció el día 16 de setiembre de 1843, aniversario de la gloriosa proclamación de la Independencia el año de 1810, México, Imprenta de Torres, 1843.

Joaquín Ladrón de Guevara, Oración cívica pronunciada el día 16 de setiembre de 1844, por el presbitero..., diputado al Congreso Nacional por el departamento de Michoacán. México, Imprenta de Vicente G. Torres, 1844.

Andrés Quintana Roo, Discurso pronunciado en la alameda de esta capital por el ciudadano.... el 16 de setiembre de 1845, solemne aniversario del glorioso grito dado en el pueblo de Dolores por los inmortales héroes de la Patria, en 1810, s. d.

José María Iglesias, Discurso pronunciado el 16 de setiembre de 1848, por el ciudadano Lic..... en el aniversario de la proclamación de la Independencia Nacional, México, Imprenta de Ignacio Cumplido, 1848.

Francisco M. de Olaguíbel, Arenga cívica pronunciada en la alameda de México el 16 de setiembre: de 1849, aniversario de la gloriosa proclamación de la Independencia, el año de 1810, por el ciudadano ..., México, Imprenta de Ignacio Cumplido, 1849.

José M. del Castillo Velasco, Oración civica pronunciada en la alameda de Mévico el 16 de setiembre de 1850, aniversario del glorioso grito de Dolores, por el ciudadano licenciado .... México, Imprenta de Ignacio Cumplido, 1850.

Epifacio J. de los Rios, Discurso pronunciado en la alameda de México el 16 de setiembre de 1851 , por el joven jalisciense don ..., México, Imprenta de Ignacio Cumplido, 1851.

Cástulo Barreda, Oración civica pronunciada en la noche del 15 de setiembre de 1853 , por $D$. ..., orador nombrado por la Junta, México, Imprenta de Ignacio Cumplido, 1853.

José María Revilla y Pedreguera, Discurso pronunciado en la alameda de la ciudad de México, el 16 de setiembre de 1857, por el C. Lic. ..., México, Imprenta de Ignacio Cumplido, 1857.

Pacual Almazán. Discurso pronunciado en la alameda de México el 16 de setiembre de 1859 por el Sr. Lic. D. ..., oficial mayor del Ministerio de Fomento, México, Imprenta de San Andrés Boix, 1859. 